\title{
Hyperkeratosis-hyperpigmentation syndrome
}

INSERM

\section{Source}

INSERM. (1999). Orphanet: an online rare disease and orphan drug data base.

Hyperkeratosis-hyperpigmentation syndrome. ORPHA:1336

Hyperkeratosis-hyperpigmentation syndrome describes a very rare hyperpigmentation

of the skin characterized by tiny hyperpigmented spots mainly on skin exposed to sunlight, together with mild punctate palmoplantar papular hyperkeratosis as a major feature. There have been no further descriptions in the literature since 1993. 